\title{
ASO Author Reflections: Dilemma of Paraaortic Lymph Node Metastases During Exploration for Suspected Periampullary Carcinoma
}

\author{
Bobby K. Pranger, BSc, and Vincent E. de Meijer, MD, PhD \\ Department of Hepatopancreatobiliary Surgery and Liver Transplantation, University Medical Center Groningen, \\ University of Groningen, Groningen, The Netherlands
}

\section{PAST}

The decision to perform a pancreatoduodenectomy for suspected periampullary cancer depends on vascular involvement, distant metastases, and lymph node metastases. Lymph node involvement of the paraaortic lymph node (PALN; station 16) corresponds with distant metastases according to the Japanese Pancreas Society Classification of Pancreatic Cancer but not in the current edition of the AJCC Cancer Staging Manual. Also, the International Study Group on Pancreatic Surgery does not include PALN in standard lymphadenectomy for pancreatoduodenectomy. ${ }^{1}$ Poor survival after pancreatoduodenectomy with positive PALN has been seen previously, but its prognostic significance has not been established. ${ }^{2}$ Some studies have identified patients who might benefit from resection, while others routinely perform a palliative bypass procedure when positive PALNs are found during exploration. ${ }^{3}$ The optimal strategy to approach PALN during surgery remains unclear.

\section{PRESENT}

This study compared the outcome of patients with suspected periampullary cancer in whom PALNs were routinely sampled during surgical exploration. Patients with PALN involvement who underwent resection had a median overall survival of 11 (95\% CI 8.8-13.2) months, compared with 7 (95\% CI 5.5-8.5) months in patients who

(C) The Author(s) 2020

First Received: 4 March 2020;

Published Online: 18 March 2020

V. E. de Meijer, MD, PhD

e-mail: v.e.de.meijer@umcg.nl received a palliative bypass $(P=0.049)$. The difference remained 2 months in a subgroup of patients who received adjuvant chemotherapy $(P=0.033)$. The survival benefit in patients who underwent pancreatoduodenectomy came at the cost of increased morbidity. Given that severe comorbidity (ASA grade $\geq 3$ ) was associated with decreased survival, we concluded that a pancreatoduodenectomy could be considered in selected fit patients with PALN metastases because it offers survival benefit, albeit at the risk of increased morbidity. ${ }^{4}$

\section{FUTURE}

Virtually all studies on the prognostic role of PALN have followed a retrospective study design. Currently, an ongoing prospective cohort study led by the Dutch Pancreatic Cancer Group is investigating the prognostic impact of lymph node metastases at the common hepatic artery (station 8), celiac trunk (station 9), and PALN on overall survival in patients undergoing pancreatoduodenectomy for suspected periampullary cancer. ${ }^{5}$ This study might further increase our understanding of the prognostic value of PALN metastases on overall survival after pancreatoduodenectomy for periampullary cancer.

OPEN ACCESS This article is licensed under a Creative Commons Attribution 4.0 International License, which permits use, sharing, adaptation, distribution and reproduction in any medium or format, as long as you give appropriate credit to the original author(s) and the source, provide a link to the Creative Commons licence, and indicate if changes were made. The images or other third party material in this article are included in the article's Creative Commons licence, unless indicated otherwise in a credit line to the material. If material is not included in the article's Creative Commons licence and your intended use is not permitted by statutory regulation or exceeds the permitted use, you will need to obtain permission directly from the copyright holder. To view a copy of this licence, visit http://creativecommons. org/licenses/by/4.0/. 


\section{REFERENCES}

1. Tol JAMG, Gouma DJ, Bassi C, et al. Non-radical resection versus bypass procedure for pancreatic cancer-a consecutive series and systematic review. Eur J Surg Oncol. 2015;41, 220-7.

2. Paiella S, Sandini M, Gianotti L, et al. The prognostic impact of para-aortic lymph node metastasis in pancreatic cancer: a systematic review and meta-analysis. Eur J Surg Oncol. 2016;42, 616-24.

3. Yamada S, Nakao A, Fuji $T$, et al. Pancreatic cancer with paraaortic lymph node metastasis: a contraindication for radical surgery? Pancreas 2009:38:e13-7.
4. Pranger BK, Tseng DSJ, Ubels S, et al. How to approach paraaortic lymph node metastases during exploration for suspected periampullary carcinoma: Resection or bypass? Ann Surg Oncol. 2020. https://doi.org/10.1245/s10434-020-08304-0.

5. Netherlands Trial Registry. NTR ID NL8424. http://www.trialreg ister.nl. Accessed at 03 Mar 2020.

Publisher's Note Springer Nature remains neutral with regard to jurisdictional claims in published maps and institutional affiliations. 